\title{
POLÍTICAS EVIDENCIADAS EM TRANSIÇÕES ADMINISTRATIVAS: EM NOME DO COMPROMISSO COM A MUDANÇA
}

\author{
Rosimar Serena Siqueira Esquinsani \\ Universidade de Passo Fundo / UPF \\ rosimaresquinsani@upf.br
}

\section{RESUMO:}

As circunstâncias que envolvem as transições administrativas, apesar de legítimas e democráticas, insinuam certo ar de ruptura em relação às políticas educacionais desenvolvidas pela administração que termina, vinculando tais políticas aos planos de governos quadrienais. Com fundamento em tal premissa, o texto reflete sobre transições administrativas, bem como as políticas evidenciadas nestes momentos de transição, apoiado em uma pesquisa empírica com abordagem qualitativa, realizada em uma rede pública municipal de ensino do interior sul-rio-grandense, a partir do mapeamento de dezoito anos (1992-2010), ou cinco mudanças de administrações municipais. O objetivo principal residiu em reconstruir a história da educação recente desta rede de ensino, acompanhando cinco mudanças de governo e suas respectivas transições administrativas, sendo que a investigação foi desenvolvida dentro de duas abordagens: a análise de conteúdo, advinda de fontes documentais (jornais de circulação local e atas de reuniões) e a revisão bibliográfica temática. Os resultados da pesquisa permitem afirmar que a ruptura na elaboração e implementação de políticas educacionais é encarada como a forma autêntica de estabelecer as diferenças entre uma administração e outra, estabelecendo um compromisso com a mudança, para que seja marcada a alteração de poder.

Palavras-chave: políticas educacionais - transições administrativas - história da educação

\section{POLICIES EVIDENCED IN ADMINISTRATIVE TRANSITIONS: ON BEHALF OF THE COMMITMENT TO CHANGE}

\begin{abstract}
:
The circumstances surrounding the administrative transitions, while legitimate and democratic, they suggest an air of disruption of the educational policies developed by the administration that ends by linking these policies to the governments plans yearly. Relying on this premise, it reflects on administrative transitions and policies highlighted in this time of transition, supported by empirical research with a qualitative approach, carried out in a public municipal school of interior South Rio Grande State, from mapping of eighteen years (1992-2010), or five changes of municipal administrations. The main objective resided in reconstructing the recent history of education in this school system, following five changes of government and their respective administrative transitions, and the research was developed within two approaches: a content analysis, drawn from documentary sources (newspapers local circulation and minutes of meetings) and the literature review topic. The research findings have revealed that the break in the development and implementation of educational policies is seen as the right way to establish the differences between one administration and another, establishing a commitment to change, so that marked the change of power.

Keywords: education policy - administrative transitions - history of education
\end{abstract}


Precariedade, desconfiança, incerteza, insegurança, instabilidade... medo. Em ano de eleições, é comum se alojar certo clima de suspeita entre os funcionários públicos vinculados a esfera federativa que terá um pleito eleitoral. A possibilidade de que, muito em breve, uma nova administração desestruture tudo que foi construído pela administração quadrienal que está findando desestabiliza, constrange e enseja insegurança.

Isto porque ronda o cenário político brasileiro certo compromisso com a mudança, alimentando o senso comum de que transições administrativas seriam atos de afronta pessoal, em detrimento de escolhas técnicas e profissionais razoáveis. Nesta direção, ainda que seja vitoriosa a mesma sigla partidária do quadriênio findo, fatores como composições da majoritária, coligações e nomeações no segundo e terceiro escalões do governo, suscitam períodos de transição.

E nem sempre este processo é tranquilo, pois há pelo menos três situações envolvidas neste rito transitivo: a) as eventuais trocas de comando não implicam apenas em cargos, funções e gratificações que mudam de mãos, mas envolvem geralmente sentimentos como gratidão e prestígio; b) processos assumidos e identificados com a administração que finda são, via de regra, colocados em segundo plano ou mesmo relegados ao esquecimento; e, c) em alguns casos, pressões para a manutenção ou substituição de nomes, bem como a demora em nomear oficialmente e divulgar os colaboradores que assumirão cargos junto à nova administração, ocasionam dúvidas e suposições, clima favorável para o surgimento de intrigas de toda ordem.

Apesar de legítimas e democráticas, as circunstâncias que envolvem as transições administrativas podem insinuar um certo ar de ruptura em relação às políticas desenvolvidas pela administração que termina, vinculando tais políticas aos planos de governos quadrienais e deixando marcas que tornam penoso este momento, pois que embasam o mesmo na prevalência de um processo de gestão centrado no peso do partido que administra (JACOBI, 2000).

E este sentimento de eterno recomeçar, que vincula políticas públicas a planos de governos quadrienais, faz com que o início de quase toda administração seja regado mais por expectativa do que por confiança; coberto de indagações mais do que respostas; mais inquietações do que segurança.

Tomando por fundamento as premissas expostas acima, o texto reflete sobre transições administrativas, bem como as políticas evidenciadas nestes momentos de transição e que, em geral, tem condicionado projetos educativos a quadriênios.

O apoio para tais afirmações vem de uma pesquisa empírica com abordagem qualitativa, realizada sobre uma Secretaria de Educação de um município de porte médio, no interior sul-rio-grandense, a partir do mapeamento de dezoito anos (1992-2010), ou cinco mudanças de administrações municipais e consequentes alternâncias de comando na referida secretaria. Apresentam argumentos empíricos para dar conta do objetivo proposto, particularmente os anos de 1992/1993; 1996/1997; 2000/2001; 2004/2005 e 2008/2009, ou o último ano de uma administração e o primeiro ano da subsequente, respectivamente.

Desta sorte, o objetivo principal residiu em reconstruir a história da educação recente desta secretaria municipal de educação, acompanhando cinco mudanças de governo e suas respectivas transições administrativas, sendo que a investigação foi desenvolvida dentro de duas abordagens: a análise de conteúdo, advinda de fontes documentais (jornais de circulação local e atas de reuniões) e a revisão bibliográfica sobre a temática.

Os resultados da pesquisa permitem afirmar que a ruptura na elaboração e implementação de políticas educacionais é encarada como a forma autêntica de estabelecer 
as diferenças entre uma administração e outra, ou entre o projeto vencedor e o projeto vencido, estabelecendo um compromisso com a mudança, para que seja bem assinalada a alteração de poder.

De outra forma, a pesquisa se sustenta na premissa de que "a investigação sobre políticas educacionais depende e sustenta a reflexão na prática" (OZGA, 2000, p. 27), sendo o olhar para e a partir da prática que dimensiona os estudos em políticas educacionais.

\section{Localizando a pesquisa...}

O município foco do estudo está localizado no interior sul-rio-grandense, com cerca de 200 mil habitantes e uma história peculiar de transições administrativas. Os últimos dezoito anos (1992-2010) foram assinalados pela alternância no poder de dois grupos políticos distintos, ambos de tendência centrista - utilizando a clássica divisão política entre esquerda e direita (BOBBIO, 1995; GIDDENS, 1996) - e liderados por dois partidos tradicionais no cenário político brasileiro.

A principal diferença entre os dois grupos referidos acima, além de discrepâncias de ordem das disputas de poder, reside nas coligações elaboradas ao longo do recorte temporal examinado: um dos grupos, liderado pelo Partido Democrático Trabalhista / PDT, estabeleceu prioritariamente coligações com partidos da chamada esquerda; enquanto o outro grupo tinha como liderança o Partido do Movimento Democrático Brasileiro / PMDB e, à despeito de coligações em nível nacional, estabeleceu laços locais com partidos da direita.

Nas eleições de 1992, o grupo capitaneado pelo PDT estava no poder, com grandes chances de eleger o sucessor do então prefeito, fato que não ocorreu e a eleição foi ganha pelo grupo opositor, liderado pelo PMDB. Tal grupo político, com alternância da composição da majoritária e dos partidos de coligação, permaneceu no poder por três mandatos (doze anos), mas em nenhum destes mandatos, conservou o mesmo secretário de educação. Nas eleições de 2004 o grupo presidido pelo PDT retorna ao poder, sendo o grupo vencedor também nas eleições de 2008. De igual sorte, em cada um destes momentos, o secretário da educação não se manteve.

Assim, seja por pressões políticas advindas da composição da majoritária e dos partidos da base aliada ou por preferências pessoais do chefe do executivo, ainda que tenhamos uma continuidade em termos de grupos políticos no poder (e apenas duas alternâncias de grupos ao longo do período analisado), a secretaria de educação trocou de mãos cinco vezes nos últimos dezoito anos.

Todavia, a troca do primeiro escalão não implicou apenas na substituição de nomes, mas também em mudanças que atingiram toda a estrutura da secretaria de educação do município. Isto porque uma secretaria não se faz apenas com o secretário, mas a partir de toda uma equipe (maior ou menor, dependendo o tamanho da rede de escolas municipais a ser gerida) recrutada basicamente de duas formas: cargos em comissão; profissionais efetivos de destaque e atuação reconhecida em determinadas áreas - atentando-se, portanto, a um critério meritocrático -, e pessoal responsável por setores iminentemente técnicos ou burocráticos, como almoxarifado e informática.

No recrutamento de pessoal por cargos em comissão o critério político é praticamente inevitável. Entretanto, no recrutamento de profissionais efetivos e técnicos que podem ser 'selecionados' e chamados para compor o órgão tanto pela sua formação e/ou especialização, quanto pela liderança que exercem junto à Rede Municipal de Ensino - 
, há uma certa liberdade de escolha, mas tais profissionais terão pouca mobilidade e praticamente nenhuma influência política. Justo pelas razões anteriormente descritas, enquanto o poder de uns vem através da legitimação do partido político, a força de outros só se sustenta pelo respeito e reconhecimento ao mérito do trabalho já desenvolvido.

Nas transições administrativas examinadas no município em relevo, fatores como a 'obrigatoriedade' da ruptura com os projetos que representavam a administração que terminava; a troca de secretários e seus assessores diretos; as propagandas de toda ordem (tanto do que foi realizado, quanto das propostas para o futuro), deram a tônica das principais políticas evidenciadas nestes momentos e que serão, neste texto, ilustradas por fragmentos empíricos.

\section{As leituras possíveis a partir de cinco transições administrativas}

Nos documentos analisados a primeira constatação possível diz respeito ao caráter atípico do primeiro e do último ano de cada administração. Se o primeiro ano é morada de um certo otimismo, refletido em propagandas e projetos apresentados à comunidade escolar, o último ano apresenta-se como um momento sombreado pelas eleições que se aproximam e, após a ocorrência destas, amarrado pela ruptura que certamente terá sequencia e abalará, em alguma medida, a vida pessoal e profissional de quem estava trabalhando na administração que finda.

Em face a este fenômeno e no caso do município examinado, percebe-se relativo abandono do órgão administrativo ao final de cada quadriênio, o que origina o discurso em torno da necessidade de continuidade do trabalho realizado na escola, enquanto aguardamse os novos ditames do órgão, pois "[...] as leis permanecem mesmo trocando a administração" (de acordo com a ata no. 15/1992, de 25 de novembro de 1992, última reunião de diretores da administração 1989/1992); o que referenda a necessidade de 'deixar a escola organizada' para a próxima administração (ata no. 15/1992, de 25 de novembro de 1992).

Tal abandono é alimentado, oportunamente, pela certeza de que haverá uma diferença de posicionamento e projetos de uma administração para a outra, ainda que a fala oficial não transpareça esta situação. Este compromisso com a 'mudança' em relação ao que o outro (partido, administração, secretário, grupo...) fazia, aborta projetos e rompe processos em nome do novo, da marca da nova administração.

Por seu turno, o compromisso com a mudança torna-se crível na medida em que recai predominantemente sobre três aspectos: a substituição de nomes e a consequente personalização da administração; a substituição de estratégias de ação e a necessidade de constante legitimação.

Para consolidar a mudança de administração, a mesma implica na obrigatoriedade da troca de pessoas que exercem cargos no órgão administrativo a cada quatro anos, obrigatoriedade produzida pela leitura que a própria gestão que inicia faz sobre os que ali estão: “[...] a professora [...] solicita compreensão por parte de sua equipe, pois está iniciando com o assessoramento de alguns colegas que permaneceram" (ata no. 108/2001, de 08 de janeiro de 2001, primeira reunião com a equipe administrativa das escolas da Rede Municipal de Ensino feita pela administração 2001/2004).

Partindo-se da premissa que, no início de uma nova administração, grosso modo os cargos em comissão já teriam sido reordenados para agraciar o pessoal vinculado ao grupo vencedor do pleito ocorrido supõe-se, com pouca possibilidade de erro, que os 'colegas que 
permaneceram' tratavam-se ou de profissionais de reconhecido mérito em sua área de atuação, ou técnicos especialistas em determinadas tarefas.

Deste modo, o pedido de desculpas narrado acima reflete o compromisso sedimentado com a mudança pois, se por um lado mantiveram-se profissionais supostamente necessários ao andamento do trabalho da secretaria de educação, por outro um pedido público de desculpas ratifica a necessidade de 'limar' nomes, personalizar a transição através da mudança de pessoal, em uma espécie de catarse onde a passagem de uma gestão para a outra somente consolida-se através da imolação. Trocam-se nomes para mostrar, deixar evidente à comunidade escolar que houve mudanças, que se vive novos tempos.

É possível verificar ainda o compromisso com a mudança através da substituição de metas, princípios, objetivos e estratégias de ação interna do órgão, condição imprescindível para a nova administração, em uma espécie de limpeza com os resquícios do antigo, já que "existem princípios que devem ser garantidos" (ata no. 108/2001, de 08 de janeiro de 2001), o que significa que outros princípios devem ser substituídos.

O compromisso com a mudança é assinalado ainda pela constante necessidade de (auto) legitimação. Ante ao receio de não serem aceitas (e portanto legitimadas) pelos professores, novas equipes tendem a estabelecer um controle externo e hierárquico sobre a rede, blindando o processo de transição: "[...] a ética é fundamental, as criticas e sugestões serão feitas pessoalmente" (ata no. 108/2001, de 08 de janeiro de 2001, primeira reunião com as equipes diretivas das escolas municipais da administração 2001/2004). Tal controle tanto se institui pela supervisão ao trabalho desenvolvido, quanto pelo estabelecimento da divisão entre quem apoiou e quem não apoiou a equipe: "informou [o secretário municipal de educação] também que as escolas receberão visitas do grupo da SME inclusive aos sábados e agradece aqueles que apostaram nesta administração" (ata no, 109/2001, de 15 de março de 2001).

Esta necessidade de legitimação como aspecto do compromisso com a mudança nutre-se também da auto-referência e do apelo ao executivo como forma de consolidação da equipe de educação que assume, evidenciada nos trechos que seguem: "com [...] o apoio da administração [...] torna-se mais fácil a realização de um trabalho de qualidade" (Secretário de Educação participa de reunião em escola, Jornal O Nacional, 30/04/2002, p.17); "a preocupação com o educar está entre as principais metas da administração [...]" (Trabalhadores em educação Infantil recebem formação, Jornal Diário da Manhã, 08 de maio de 2001, p.03); "todo trabalho realizado pela Secretaria Municipal de Educação tem o apoio da comunidade e da administração [...]" (SME promove encontro de diretores para avaliar ação pedagógica, Jornal O Nacional, 22 e 23/06/2002, p.10); "todo trabalho realizado pela Secretaria Municipal de Educação tem o apoio da comunidade e da administração [...]" (Secretaria Municipal de Educação promove reunião de coordenadores, Jornal O Nacional, 19/06/2002, p.12); "todos os trabalhos realizados pela Secretaria Municipal de Educação têm como objetivo a qualidade de ensino e são apoiados pela administração [...]" (SME promove encontro de integração com [...], Jornal O Nacional, 11/12/2002, p.11).

Além dos processos de alternância e substituição de metas, nomes e cargos e dos discursos de legitimação, as transições administrativas examinadas ainda foram palco de extensa propaganda, tanto por parte da administração que se encerrava, como da administração que se iniciava. Tais propagandas carregavam duas tônicas diversas: a prestação de contas e a apresentação de propostas.

No tocante a administração concluída, parece existir a obrigação de prestar contas do trabalho desenvolvido, das conquistas, das realizações... 
De 1993 até este ano [1996], houve uma diminuição das cedências de professores, monitores e funcionários [...] Além disso, houve a regularização dos quadros de professores nas escolas, sendo obrigatória a carga horária mínima, outro 'gargalo de estrangulamento' dos sistemas de ensino (Ensino Municipal: ações para melhorar o ensino [...]. Jornal Diário da Manhã, 28/11/1996, p.08).

Esta prestação de contas - discurso praticamente compulsório para quem encerrava a administração -, carregava ainda um ar nostálgico que se materializava em agradecimentos:

[...] o professor [...] coloca que a relação entre professores e Secretaria deve ser muito estreita, com trabalho em parceria. Agradeceu o apoio e a confiança nele depositada, resultante da melhoria na educação observada e sentida por todos. Tal melhoria deve-se ao professor na sala de aula, ao trabalho dos supervisores, diretores e Secretaria de Educação, com sua equipe de supervisores (ata no. 53/96, de 18 de dezembro de 1996 última reunião de diretores da administração 1993/1996).

No caso emblemático do município examinado, mesmo na ocorrência de reeleição e recondução ao executivo do mesmo partido político ou até do mesmo prefeito, o fim de um quadriênio foi sempre assinalado por alguma forma de rito de mudança na secretaria de educação. Tal rito pode ser exemplificado no excerto a seguir pelo pedido de sugestões e propostas, dando a entender que algo será modificado...

“[...]a Secretaria de Educação (SME), realizou uma reunião com todos os diretores das escolas municipais. O encontro foi no plenário da Câmara Municipal de Vereadores, e teve objetivo de levantar sugestões e propostas para a continuidade da educação municipal, além de avaliar todos os programas desenvolvidos pela secretaria na atual gestão do prefeito [...] O secretário de educação, [...], destacou que a SME tem usado a estratégia de realizar reuniões conjuntas para discussão e planejamento das ações educacionais" (ata no. 25/2008, de 13 de novembro de 2008)

Ainda em relação a propaganda, no que diz respeito a administração que se iniciava, era muito comum a utilização dos primeiros momentos de contato com a rede de ensino, para a divulgação das iniciativas e projetos, sobretudo evidenciando as novidades, o diferencial em relação ao que tinha sido desenvolvido até então:

a seguir as professoras [...] e [...] falaram sobre o projeto 'Quem participa constrói educação de qualidade', que tem como objetivo: "Proporcionar momentos de reflexão sobre as necessidades técnicas, administrativas e pedagógicas das escolas da Rede Municipal de Ensino, visando a um processo participativo e coerente na elaboração do Plano de Ação da Secretaria Municipal de Educação em busca da qualidade do ensino". As escolas deverão reunir a comunidade escolar, com o propósito de discutir suas necessidades, posteriormente será realizado um 'fórum', com representantes de cada segmento, para socializar suas discussões e encaminhamentos. Sistematizando as idéias para elaboração do Plano de 
Ação da SME, com metas de curto, médio e longo prazo (ata no. 55/97 de 27 de fevereiro de 1997).

Percebe-se, ainda, pelos documentos dispostos à análise, que a materialização de um rito de transição poderia se dar de forma direta, através de reuniões que apresentem a nova equipe e as novas propostas; ou de forma indireta, em celebrações e reportagens, mas sempre deixando claro que o período anterior fora encerrado.

Este encontro proporcionou momentos de reflexão sobre a ação pedagógica, no processo ensino-aprendizagem. Após uma apresentação musical do Coral das Escolas Municipais, o secretário municipal de Educação, [...], apresentou aos professores dados da Rede Municipal de Ensino e as metas do Poder Público Municipal em relação à educação. Também presente, o Prefeito Municipal, [...], ressaltou que das três principais prioridades em seu governo, uma é a educação (ata no. 02, de 17/02/2005 abertura do ano letivo, primeira atividade coletiva da administração 2005/2008)

Mesmo que as atividades beirassem a normalidade, como uma simples entrega de agendas, tal situação também era utilizada para compor o rito transitivo e, sobretudo, para mostrar que um período havia se encerrado;

[...] uma extensa programação, incluindo reuniões pedagógicas, palestras e celebrações. O objetivo foi iniciar as aulas na rede municipal de ensino, renovando a determinação de avançar pedagogicamente. A Secretaria Municipal de Educação (SME) participou desta programação e desejou boas vindas [sic] aos professores e comunidade. $\mathrm{Na}$ oportunidade, ocorreu ainda, a entrega de agendas informativas ao corpo docente (Atividades marcam abertura de ano letivo, Jornal Diário da Manhã, 03 de março de 2001, p.03).

Também em relação às propagandas das propostas da administração que se iniciava, mesmo quando não havia uma ruptura ou troca de partido político no governo, ainda assim havia a necessidade de demarcar com nitidez qual o momento em que um projeto cede lugar a outro

Nesta segunda-feira, (15/12), o prefeito municipal, [...], anunciou em seu gabinete, a nominata dos secretários que irão compor a administração nesse final de governo e no próximo mandato que inicia em primeiro de janeiro. Os novos gestores públicos já assumem nesta terça-feira, (16/12), às 11 horas, após ato de posse que também acontece no gabinete do prefeito (ata no. 02, de 15/12/2008).

É preciso tornar público que ocorrerão mudanças. Tais mudanças implicam em que alguns projetos sejam substituídos ou cancelados, novos projetos sejam criados e que alguns sejam redimensionados ou retomados. Tal publicização de intenções apenas corrobora no já demonstrado compromisso com a mudança...

a Secretaria de Educação (SME), realizou reunião de abertura do ano letivo com as equipes gestoras das 36 escolas municipais de ensino fundamental. Após saudar a presença dos educadores, a secretária de Educação, professora [...], destacou que a SME está a disposição das 
escolas para a realização de mais um ótimo ano letivo. Em seguida, ela passou a palavra para os coordenadores da secretaria e suas respectivas equipes. Na reunião foram tratados os mais variados temas, objetivando o planejamento deste ano letivo. A retomada do programa de formação continuada de professores [...] também foi abordada. Na área da educação especial, foi destacado que até o mês de junho, o município está recebendo mais cinco Salas de Recursos, espaço para o trabalho com alunos especiais, além de ser anunciado o novo projeto da secretaria de "Esporte Adaptado", para crianças especiais desenvolverem todas suas potencialidades (ata no. 03, de 12/03/2009, grifos meus)

Os elementos empíricos examinados apontam, unanimemente, para a naturalização e necessidade de um rito de transição entre uma administração e outra. Tal rito legítimo, contudo, é assinalado fortemente pelo compromisso com a mudança e com a ruptura com o que estava sendo feito. Nada deve ficar no lugar e, se ficar, deve ser renomeado, reconfigurado, ajustado.

O rito transitivo configura-se, desta forma, pelo final de um projeto e início de outro. Anunciar o novo faz parte dos discursos de todas as administrações analisadas e, nesta direção, impregnam de sentido a paráfrase de Certeau (2002, p.300) como se para um período viver outro tivesse que morrer.

\section{Conversando sobre o tema}

As cinco mudanças de governo acompanhadas permitem a leitura de que há um rito transitivo, legítimo e democrático, que baliza o fim de uma administração e o início de outra. Todavia, este rito transitivo é assinalado quase exclusivamente pela ruptura, como se a condição de transição fosse a idêntica condição de ruptura, de mudança, de quebra, de desmanche...

a noção de transição contém a ideia de ruptura, mas a transcende. Tratase [...] de organizar a transição para um outro, alternativo em seus fundamentos. Na medida em que ela poe o acento no segundo termo do par destruição/criação, está em consonância com a própria noção de governabilidade. Trata-se evidentemente de evitar uma situação de caos sistêmico, no qual as antigas regras já não funcionam, mas as novas não adquiriram ainda eficácia e legitimidade (GUIMARÃES, 2004:36-37).

O compromisso com a ruptura, com a mudança, estabelece as diferenças entre o projeto vencedor e o projeto vencido, ainda que não haja alternância no poder nem de partido, tampouco de grupo político. A ruptura e o estabelecimento do novo dão as cores e os tons que definem quando uma época inicia (obrigatoriamente sobre as cinzas da anterior).

Como um terreno de disputas, as políticas educacionais são "um processo mais do que um produto, envolvendo negociação, contestação ou mesmo luta entre diferentes grupos" (OZGA, 2000, p.20), sendo que sobre este terreno contestado, as mudanças de governo e a ruptura de projetos figuram como apenas mais um ingrediente.

Entretanto, esta não parecer ser uma prerrogativa exclusiva do município examinado, a análise local apenas empresta exemplos para situações que, segundo a literatura consultada, ocorrem em diferentes níveis federados e de forma ordinária, comum, 
cotidiana. Em relação ao assunto Guiomar Namo de Mello afirma que a descontinuidade na elaboração e implementação de políticas educacionais

[...] parece ser (...) uma tônica permanente no cenário administrativo nacional, por força do atrelamento do estado ao clientelismo político. Mudanças de governo, no Brasil, implicam interrupção dos projetos de inovação e melhorias do ensino sem avaliá-los, só porque foram iniciados por outras administrações (1992, p.204)

Estabelece-se, assim, as diferenças entre vencedores e vencidos. Tal prática reforça o alerta de Mendonça (2001) acerca da patrimonialização do Estado e do tom autoritário e estamental que o mesmo assume, assim como das políticas implementadas pelo governo que por hora administra a máquina estatal, pois...

É essa maneira autocrática e autoritária de funcionamento do Estado, característica do governo estamental, que permite que as políticas públicas, de que a gestão democrática do ensino público é apenas um exemplo, sejam constantemente alteradas, ao sabor das conveniências políticas. O governante dita à sociedade a sua vontade pessoal como se estatal fosse, numa versão adaptada e moderna do coronelismo, elemento que participa da estrutura patrimonial e que transforma o governante no dono do governo. Esse poder pessoal acaba permitindo a descontinuidade na sustentação de políticas educacionais, mencionada como fator que dificulta a implantação de mecanismos de gestão democrática. Cada secretário, cada governador ou prefeito tem o seu plano, a sua proposta curricular, a sua lei, julgando, com a arrogância típica de quem se pensa dono do cargo que ocupa, que são os seus instrumentos os que melhor respondem às necessidades da população [...] (MENDONÇA, 2001, p. 97).

Ainda nesta linha de reflexão, corrobora também Cunha (1994, p.25) quando nomeia tais práticas como administração zig-zagueante. O autor refere-se, assim, à prática segundo a qual, por diferentes razões, cada secretário de educação orienta o seu mandato de acordo com um programa próprio (pessoal ou partidário) de gestão da educação. Tal programa muda a cada quatro anos, ou mais rapidamente, no caso do secretário não permanecer no cargo durante todo o mandato do prefeito (mas poderia ser governador, presidente...), o que prejudica a avaliação das políticas educacionais e impede que seus eventuais efeitos positivos se reproduzam, tenham continuidade ou ganhem consistência.

Neste sentido, hodiernamente é muito comum que campanhas eleitorais sejam embasadas em dois tipos de discurso: a continuidade de práticas que caem no gosto popular ou a personalização de políticas públicas. É frequente, assim, o uso de argumentos na campanha como "quando eu for prefeito, não vou alterar tal programa, aliás, vou melhorá-lo e ampliá-lo", ou ainda "em meu governo, implementei tal programa", em uma clara referência ao personalismo de políticas públicas e ao já esperado compromisso com a mudança, que tem feito com que cada vez mais eleitores respaldem políticos que prometam não alterar o que está apresentando resultado.

Isto em razão de que cada administração acaba trazendo consigo o germe do novo, mas muitas vezes este novo implica na desconsideração pela trajetória histórica do grupo constituinte da rede de escolas. 
Cada mudança de governo representa um recomeçar do "zero", negandose a história que, no entanto, está lá - na escola, na sala de aula, nos saberes do professor. O essencial dessa descontinuidade é o eterno recomeçar, como se o passado pudesse ser anulado; repetição constante do "novo" para manter a eternidade das relações - de poder - atuais (COLLARES; GERALDI; MOYSES, 1999, p.209).

A descontinuidade político-administrativa, somada à própria tradição clientelista que qualifica o campo político brasileiro, tem reflexos importantes na configuração da arena educacional, tornando-a extremamente vulnerável às ações demandadas pela disputa político eleitoral na qual o controle do sistema de ensino representa uma moeda de alto valor, seja para a legitimação dos líderes políticos do momento, seja para a desautorização de seus opositores (ou antecessores). Mas isto tudo não se dá sem um preço a pagar. E, infelizmente, parece que ao longo história recente, quem tem arcado com este ônus é a qualidade da educação pública, pois...

[...] na forma de produção capitalista, as hegemonias se impõem sem que qualquer partilha se dê, resultando muito mais de uma forma de apropriação do todo por uma parte da sociedade, segundo interesses de classe, de gênero, de etnia etc. A política contemporânea é, portanto, uma política privada que, com o argumento nem sempre real de atender à maioria, prioriza interesses específicos. Assim, difunde-se como necessidade social o que, na verdade, é mera demanda de um grupo (COLLARES, GERALDI e MOYSES, 1999, p.208).

Por esta razão, não raras vezes o especifico, o pessoal se sobrepõe ao todo, em nome da democracia representativa e da autorização que ela passa, aos 'eleitos' por pleitos quadrienais, de gerirem situações, encamparem e difundirem ideias, realizarem ações especificas, como se isto fosse o interesse de um coletivo.

Braga, em meados da década de 1980, ao falar sobre o MEC e a alta rotatividade dos ocupantes dos seus cargos o que, na visão do autor, impede a continuidade administrativa e compromete a seriedade de sua programação de trabalho, salientava o efeito predatório que as constantes alterações na agenda de trabalho do órgão administrativo da educação tinha sobre a educação como um todo, “...dilacerando suas ações, pulverizando seus recursos, dando violento tom de precariedade aos seus programas e projetos" (BRAGA, 1984, p. 92), o que acabava por gerar uma certa consequência natural por parte das escolas, que seria "[...]a indiferença e a apatia com que recebem, ciclicamente as inovações oriundas do MEC[...] " (idem), pois, pergunta Braga, "[...] que credibilidade pode ter uma proposta de ação cuja vida média vai se igualar a das mariposas?" (idem)

Esta certeza da ruptura ou da troca de diretrizes após quatro anos de governo, acaba por gerar consequências nefastas, sendo que talvez a mais corrosiva delas seja o descomprometimento, a indiferença e a apatia (BRAGA, 1984) de professores e da comunidade escolar em geral com os projetos propostos, pois sabem que tal agenda durará somente quatro (?) anos, o que torna compromissos e cronogramas, sejam de propostas de formação docente ou de práticas administrativas de gestão escolar, atos mecânicos e formais.

Agrego, ao acima exposto, o indicativo de fatores que acenam para a descontinuidade e que no entender de Collares, Geraldi e Moyses (1999) levam a esse descomprometimento da "base" com os projetos educativos para a educação pública: 
- a constante interrupção de projetos, sem escuta e avaliação prévias entre os participantes; (...)

- alterações de formatação de programas e projetos e forma de organização de órgãos públicos responsáveis pela execução dos planejamentos;

- a vulgarização de modelos científicos, tornados "modismos" e transmitidos como "receitas", em panacéia para todos os problemas (p. 209)

O projeto educativo embasado no partido que administra, é motor de rupturas, ora por que " descobre-se a roda" ou uma grande teoria educacional, revolucionária e inovadora (!), ora por que um novo governo assume para tudo mudar, mantendo a mesmice da escola e suas mazelas, tudo isto muito bem respaldado pela representatividade que o pleito democrático legou ao "novo" grupo.

Por outro lado, rupturas podem estar no seio de um mesmo projeto educativo, pretensamente uno. Segundo Mendonça, "[...] a permanência de um partido no governo de uma unidade da Federação ou de um município, (...) não é condição suficiente para que a continuidade de políticas educacionais seja uma realidade[...] " (2001, p.98)

Estas rupturas podem ter nascedouro nos mais diferentes locais: estratégias mal formuladas de operacionalização; disputas políticas internas, vaidades inerentes à cúpula da "hierarquia" responsável pela implementação de um projeto educativo, a partir da proposição de políticas públicas para a educação, ou mesmo na personalização do poder, assumida não por um grupo, mas por uma única pessoa, ainda citando Mendonça, “[...] importante ressaltar que, em relação à questão da descontinuidade na execução de políticas públicas, o problema se localiza na pessoa do governante, mais que no grupo político ou no partido que lhe dá sustentação[...] (2001, p. 97) e cada uma pode implicar em um sem número de desdobramentos.

Porém é preciso considerar duas situações em relação ao rito transitivo: a absoluta legitimidade do mesmo e a tendência que nos assola em considerarmos toda a mudança ou ruptura de forma pejorativa.

Quanto a primeira situação reitero que o partido vencedor, legitimado pelo resultado das urnas, tem a prerrogativa de modificar nomes e cargos; propor; reformular e mesmo cancelar projetos e programas. Sem querer entrar em um debate que seria demasiadamente longo para as pretensões deste artigo - ou a discussão da democracia representativa -, é oportuno mencionar que o jogo político deve ser respeitado ainda que implique, também, na ocorrência destes ritos de transição. A questão é: apesar de legítimo, o bom senso deveria conduzir o processo de transição de um governo por outro.

Quanto a segunda situação - a tendência em considerarmos toda a mudança ou ruptura de forma negativa ou positiva a priori -, carece de um cuidado quando for generalizada, tendo em vista que "[...] muita da história sobre política educacional tem sido escrita como a história do progresso, na qual o desenvolvimento do sistema é visto como um tipo de crescimento natural" (OZGA, 2000, p.209).

Trata-se de uma análise embasada no legado positivista da cronologia, linearidade e salvacionismo, onde caminharíamos todos, fatalmente, em direção ao progresso, esquecendo-nos das contradições inerentes ao próprio ser humano e ao contexto, elementos básicos para uma leitura dialética da(s) realidade(s). O fato do novo chegar ou de haver ruptura com práticas até então instituídas não significa, por si só, nada de progresso ou retrocesso. Para fazer este exame há a necessidade do cotejamento de diversos dados que fogem ao dualismo romper com o velho e instaurar o novo. 
$\mathrm{Na}$ mesma direção da análise anterior, é oportuno explicitar que podem haver conjunturas onde a manutenção de uma política para a área da educação seja tão contrária aos interesses da maioria da comunidade escolar, que a ruptura com a proposta em curso para a implementação de uma nova significará ânimo renovado para grande parte dos professores, funcionários, pais e alunos.

São os casos em que a diferenciação entre vencedores e vencidos, materializada pela ruptura, é aguardada com alguma ansiedade por parte dos diretamente afetados. Tratam-se de conjunturas onde a proposta educacional quadrienal foi construída em gabinetes, sem espaço para o diálogo com os interessados; vem de encontro a uma trajetória democrática; altera conquistas históricas (como salários e planos de carreira); ou ainda por ser proposta por um governo com alto índice de rejeição popular.

No dizer de Collares, Moyses e Geraldi,

[...] as rupturas, que são propiciadas pelos acontecimentos, pelas experiências planejadas ou ditadas pelo acaso, constituem a essência da continuidade, ao tecerem novas possibilidades de caminhos por onde a vida possa fluir, nos diferentes e incertos modos de andar a vida (1999, p. 217)

Ainda que ruptura carregue em si o germe do negativo - seja pelas experiências que normalmente são relatadas, seja pela força do atrelamento estatal a conceitos como patrimonialismo e clientelismo -, este caráter negativo apenas se consolida na medida em que alguém atribua tal valor a ruptura. Isto porque as generalizações são perigosas. Uma história tem sempre dois lados.

Se a ruptura marca de forma indelével os ritos transitivos no município examinado é em face de uma relação de forças que não pode ser rotulada como avanço ou retrocesso, até porque a realidade é muito mais rica e dinâmica que as mudanças de gestão e administração municipal.

\section{Para concluir...}

Os documentos empíricos apontam para a seguinte conclusão: a ruptura na elaboração e implementação de políticas educacionais, materializadas em programas e/ou projetos, dentro da demanda de políticas públicas para a educação, é encarada como a forma autêntica de estabelecer as diferenças entre a administração que se encerra e a que assume.

Por força desta orientação, há o estabelecimento de um compromisso com a mudança, para que seja assinalada indelevelmente a alteração de poder. Todavia, através do cotejamento com a literatura sobre o assunto, é possível verificar que em outras realidades além da analisada, tal prática também é utilizada e, além do mais, naturalizada como um legítimo elemento da transição administrativa.

Mas, seria possível romper com a tradição velada de mudar/substituir projetos em nome do partido vencedor? Encampo a bandeira de que as políticas públicas para a educação, bem como as ações encetadas nesta área, deveriam atender a políticas assumidas pela comunidade (no mínimo) escolar, pela rede de escolas e seus professores e não a planos de governo, que têm a vida 'útil' vinculada a este governo.

O eterno recomeçar, que os autores mencionam, faz com que o início de quase toda administração seja mais expectativa do que confiança, mais indagações do que respostas, mais indeterminações do que segurança. Diante dessa situação, o descomprometimento de 
governantes com a educação, com a continuidade de projetos educativos ou com uma séria e sistemática discussão a partir da comunidade escolar sobre a validade ou não da continuidade destes, passou a figurar quase que como uma "cultura" política brasileira.

Que rupturas e permanências de projetos educativos - apesar de prerrogativas legítimas dos governantes eleitos -, sejam sobretudo e prioritariamente frutos de discussões e consensos 'provisórios' e coletivos com toda a rede de escolas e comunidade escolar e não de decisões de governantes personalistas. E, por fim, considero que é preciso pensar seriamente em possibilidades reais de construção de espaços de discussão e decisões coletivas em se tratando de políticas públicas, possibilidades estas que dormitam a espera da boa vontade política dos eleitos.

\section{Bibliografia:}

BOBBIO, Norberto. Direita e esquerda: razões e significados de uma distinção política. São Paulo: UNESP, 1995. 129 p.

BRAGA, Ronald. O MEC e o Poder. Educação Brasileira - CRUB: Conselho de Reitores das Universidades Brasileiras.V. 6. no. 13 - 2o. semestre de 1984. Brasília, 1984.

CERTEAU, Michel de. A escrita da História. Rio de Janeiro, Forense Universitária, 2002.

COLLARES, Cecília Azevedo Lima, MOYSES, Maria Aparecida Affonso e GERALDI, João Wanderley. Educação continuada: a política da descontinuidade. Educação $e$ Sociedade, vol.20, no.68, p.202-219, dez. 1999.

CUNHA, Luiz Antônio. Zig-Zag no primeiro grau: o Rio de Janeiro nos anos 80. Revista do Rio de Janeiro, $\mathrm{n}^{\circ}$ 3, pp. 21-26, 1994.

GIDDENS, Anthony. Para além da esquerda e da direita: o futuro da política radical. São Paulo: UNESP, 1996. 296 p.

GUIMARÃES, Juarez. A esperança equilibrista: o governo Lula em tempos de transição. São Paulo: Editora Perseu Abramo, 2004.

JACOBI, Pedro. Educação, ampliação da cidadania e participação. Educação e Pesquisa, jul./dez. 2000, vol.26, no.2, p.11-29.

MELLO, Guiomar Namo de. Autonomia da escola: possibilidade, limites e condições. In: VELLOSO, Jacques [et. al]. Estado e Educação. Campinas: Papirus, 1992.

MENDONÇA, Erasto Fortes. A regra e o jogo: democracia e patrimonialismo na educação brasileira. Campinas, SP: FE/ UNICAMP, 2000.

Estado Patrimonial e Gestão democrática do ensino público no Brasil. Educação e Sociedade. Ano XXII, no. 75. Campinas: Cedes (Centro de Estudos Educação e Sociedade), agosto/ 2001.

OZGA, J. Investigação sobre políticas educacionais: terreno de contestação. Portugal, Porto Editora, 2000. 


\section{Fontes Documentais}

Livro de Atas das reuniões entre a Secretaria Municipal de Ensino do município examinado e a equipe diretiva das escolas da Rede Municipal de Ensino, 1989 - 2004.

Livro de Atas das reuniões entre a Secretaria Municipal de Ensino do município examinado e a equipe diretiva das escolas da Rede Municipal de Ensino, 2005-2009.

Jornal Diário da Manhã (DM)

Jornal O Nacional (ON)

Artigo recebido em: 03/03/10

Aprovado em: 18/05/10 